\title{
COHESION AND COHERENCE IN THE WRITINGS OF IRANIAN EFL STUDENTS
}

\author{
Arab Zoozani \\ M.A. (PhD. Candidate), Ferdowsi University, Mashhad,Iran \\ Pahlavannejad M. \\ (PhD.), Professor of Ferdowsi University, Mashhad, Iran
}

\begin{abstract}
This study was conducted in to investigate the relationship of cohesive chains and chain interaction to the coherence of texts. To do this, the following procedure was followed. First, 95 EFL students were asked to write a composition on a particular topic. These texts were scored by three experienced raters based on their perceived degree of coherence. The texts were then ordered from high to low. Thirty high-rated texts were labeled as group A, and thirty low-rated texts were labeled as group B. These texts were analyzed for the presence and frequency of cohesive chain and chain interaction based on the model proposed by Hassan (1989). After collecting the data and statistically analyzing them, the results showed that the texts getting higher coherence scores had a higher proportion of relevant tokens to peripheral ones and a higher proportion of central tokens to non-central ones in comparison to the low-rated texts. Therefore, cohesive chain and chain interaction can be used as an indicator of coherence and has pedagogical and theoretical implications.
\end{abstract}

\section{Council for Innovative Research}

Peer Review Research Publishing System

Journal: Journal of Advances in Linguistics

Vol 2, No.1

editor@cirworld.com

www.cirworld.com, member.cirworld.com 


\section{Introduction}

Turning to the history of linguistics, we can see that before Chomsky, the structuralist view of language, taking the sound system of language as the pivot of its studies was dominant. However, Chomsky brought a great shift in the field by proposing concepts such as : 'universal grammar', 'language acquisition device, principles and parameters, etc. Later, many scholars proposed a need to study 'the rules of use'; which means, what language users really produce is not sentences in isolation, but discourse units in context (Apple \& Mysekn, 1987; Leech, 1983; Hymes, 1972). Such an approach brings into consideration a number of issues which did not receive much attention into the formal linguistic description of structural syntax and semantics. According to Brown and Yule (1983),"the discourse analyst treats his data as the record (text) of a dynamic process ... to express meanings and achieve intentions" (p.22).

Two main properties of any text are 'cohesion' and 'coherence'. Coherence is underlying semantic relations, which turns the words, sentences, or propositions into a unified, understandable whole, and is achieved by interpreting each individual sentence and relating these interpretations to one another (Witte \& Faigley, 1981 ; Van Dijk, 1977). However, cohesion as 'surface-level ties' link separate phrases, clauses, sentences, and even paragraphs into a unified discourse (Gumpers et al., in Tannen, 1984).

The world, and particularly the world of education, is made up of spoken and written discourse (communication). The success of discourse is not something we can just assume, we need to know what properties it must have in order to be successful. Thus, some studies are essential to light up some unknown aspects of coherence, and it has implications for language teaching in general and teaching writing in particular The claim that coherence is ultimately based on the assumption that when speakers speak, they say things that cohere to each other cannot help the teacher or the students. A teacher cannot stand with the assumption of coherence or non-coherence, when picking up a written text by a student. One way to explain why the discourse does not work as the student wishes it to work is to look up the meaning relations. Teachers can do this by concentrating on the language of that text as meaning is constructed by language.

Many studies have been conducted since this functional view entered in the field of linguistics, taking it as the theoretical basis of the researches. A lot of scholars have centered their studies on the practicality of functional grammar in teaching language. However, by assuming that production difficulties arise from not knowing the required vocabulary or structures, foreign language teachers may overlook the difficulties the students have in making meaning relations within discourse. Though students may have a good command of language in terms of grammar, vocabulary, etc., the problem in producing unified texts is still easily tangible. As teachers, we should notice that a clear understanding of the formal connections between sentences may help to explain one of the ways in which foreign language students sometimes write supposedly connected sentences, each of which is well-formed in itself but which somehow adds up to a very strange discourse (Cook ,1989).

The most influential studies of textual analysis techniques, in terms of current appeal in applied linguistics have been the approaches of Halliday and Hassan (1976, 1987, 1989 ). This study is conducted based on the theory which was presented by Hassan in 1989. They provided a detailed taxonomy of the types of cohesive ties used in English texts including reference, substitution, ellipsis, conjunction and lexical cohesion between the messages of a text. These ties are the principles of semantic relations which are classified as co-referentiality, co-classification, and co-extension, Hassan (1989). According to her , a tie is usually formed by two items that function as the two ends of the tie- item ' $A$ ', and item ' $B$ ', which spatially separated from each other. If both ' $A$ ' and ' $B$ ' refer to the same identity in the real world, this semantic relation will be co-referential. The tie is co-classification when the things, processes, or circumstances to which ' $A$ ' and ' $B$ ' refer belong to an identical class. Co-extension happens when ' $A$ ' and ' $B$ ' are members of non-identical but related class of things, events, etc. These semantic relations are precisely what ties the two members of a tie, and the existence of such ties is essential to texture.

\section{A brief review of the literature}

In line with Hassan's (1989) model, the researcher limited this study to what she presents in her model as the factors affecting coherence. To have a better glimpse of what area this study is associated with, some investigations conducted in line with ours, will first be briefly pinpointed. During the past decade, there has been substantial growth in interest in the analysis of texts of various types. To a large extent, emphasis has been given to the analysis of spoken texts (e.g Sacks, Schegloff \& Jefferson, 1974; Tannen, 1981).More recently, attention has turned to the analysis of written texts (e.g. Van Dijk, 1985; de Beaugrande \& Dressler, 1981; Van Dijk, 1985; Halliday \& Hassan, 1976, 1989; Halliday, 1994). Much of the work undertaken has in fact been concerned with theory, but some effort has been made not only to permit access to teachers, but also to translate theory into practice in the form of materials available to teachers of L2 and L1 writing (e. $g$. McCarty \& Carter, 1994;Liu,2003; Hyland,2005; Rost,2005;).

Most of the accounts of text analysis have been in terms of linguistic theories of text, i.e. textual analysis techniques which parallel sentence analysis techniques. These approaches are even sometimes called text 'grammars'. More recently, the properties of texts have been examined in terms of the linguistic property of cohesion (Halliday \& Hassan, 1978, 1989; Hassan, 1978; Halliday, 1994). The new approach to text analysis is believed to be included by systematic linguistics.

The systematic (functional) linguistics has been described as a functional-semantic approach to language which explores both how people use language in different contexts, and how language is structured for us as semiotic system. As linguistic approach to meaning in text, systematic linguistic has common ground with text grammarians and discourse analysts from a range of perspectives (e.g., Chafe, 1980 ; Biber,1986;Schiffrin,1994; Thompson,1996 ; Butler,2003b; 
Dong,2005 ). However, to know what aspects of the theory have been central in this research, they are briefly tackled in the following.

\section{Theoretical framework}

Based on this theoretical framework proposed by Hassan (1989), a cohesive chain is formed by a set of items each of which is related to the others by semantic relations of co-classification, co-referentiality, or co-extension. Taking these types of cohesive chains into account,Hassan puts them in two categories, 'Identity Chains' and 'Similarity Chains'.

The relation between the members of an identity chain is that of co-reference; every member of the chain refers to the same thing, entity, or event in the world. The members of similarity chains are related to each other either by coclassification or co-extension. Such a chain is made up of items that refer to non-identical members of the same class of things (co-classification) or to members of non-identical, but related class of things, events, etc. (co-extension). Although the chains go a long way toward building the foundation for coherence, they are not sufficient. We need to include some relations that are characteristics of those between the components of a message. This relation is referred to as 'chain interaction' (Hassan, 1989). What Hassan means by chain interaction is relations that bring together two or more distinct chains. On the basis of this taxonomy, Hassan concludes that variation in coherence is the function of variation in the "cohesive harmony" of a text, while cohesive harmony is the sum of the following related features:

1-The lower the proportion of the peripheral tokens to the relevant ones, the more coherent the text is likely to be. By peripheral tokens she means all those tokens that do not enter into any kind of chain and relevant tokens are all tokens that enter into identity or similarity chain.

2. The higher the proportion of central tokens to the non-central ones, the more coherent the text is likely to be. Here, central tokens are those relevant tokens that interact and non-central tokens are those relevant tokens that do not interact.

Hassan claims that using this framework, we can state fairly definitely what the linguistic correlate of variation in coherence will be (Hassan, 1989, p. 93). Now, we can conclude that a text which is more congruent with the mentioned features in terms of its linguistic aspects is likely to be more coherent. The aim of this study is to see whether the text taken as more coherent, based on our impressionistic judgments, is in a better harmony with the features mentioned by Hassan (1989), in comparison to a text which is judged as less coherent impressionistically.

One important aspect of education is the production of natural discourse. A teacher aims to educate and train in such a way that the students are able to talk and write about their selected topics as native speakers as much as possible. Moreover, the incoherence of discourse is often a pointer to an inability to organize the relevant meanings in relation to each other. A teacher can assist by pointing out what semantic consequences the choice of a particular word might have. We have to account for our intuition of coherence, and thus gain insights into the needs of the language learners who are supposed to produce coherent discourse, not isolated sentences. In order to do this, we have to find linguistic facts that can be correlated with variation in coherence.

Based on the previous discussion the following research questions were asked in this study:

1. Do texts scored higher by experienced raters based on their perceived degree of coherence have a higher proportion of relevant tokens to the peripheral ones?

2. Do texts scored higher by experienced raters based on their perceived degree of coherence have a higher proportion of central to non-central tokens?

Accordingly, there were two hypotheses formulated in this study:

Hypothesis I: The texts which have been given higher coherence scores will show lower proportion of peripheral tokens to the relevant ones.

Hypothesis II: The texts which have been given higher coherence scores will show higher proportion of central tokens to the non-central ones.

\section{Methodology}

The subjects of this study were 95 undergraduate students in Torbat-e- Heidariah Azad University. They were randomly selected from among a population of 230 students majoring in Teaching English as a Foreign Language in that university. To select the subjects, the researcher picked the odd numbers from a list on which all the students' names were listed. In addition to this sample, five English teachers in Torbat University helped the researcher in this study. Three of them participated in the main experiment, for scoring the students' written texts.

Three fair copies of the texts written by the students were prepared by the researcher and were given to the selected raters. In addition to these, a small paper instructing the scorers about scoring was given to the raters. They were asked to score the texts on a scale of to 5 , based on their perceived degree of coherence taking the points mentioned in the instruction-paper into consideration (see Appendix C). Therefore, each writing received three scores. The mean of these scores was taken as the coherence score of the text. The texts were ordered based on their coherence scores from high to low. 30 tests from the top (getting the highest scores) and 30 from the bottom (getting the lowest scores) were selected for later analysis. They were labeled as group 'A' and group 'B'. Ten texts were omitted from the analysis either because subjects had misunderstood the title or because they were scored significantly different by different scorers. The remained 50 texts Lower analyzed based on Hassan's (1989) model. For text analysis, first the lexical rendering was done on all 
texts. In this stage the content words and the words which were the interpretation of a grammatical devices were extracted.

The similarity chains and identity chains were found and listed on a paper. The tokens that entered into any of these chains were based on the definition, the relevant tokens. The remained ones were peripheral tokens. To enumerate the central tokens, the chain interactions were determined. That is, wherever at least two members of one chain had stood in the same relation to two members of another chain, it was taken as chain interaction. Those members of the chain that had entered into interaction were taken as central tokens; the remaining relevant tokens were non-central ones .To illustrate the process of text analysis, two samples, one text from group A and one from group B, are analyzed based on Hassan's (1989) model .

\section{A sample text from Group A.}

There are five people in my family. My father is a teacher. He teaches English. My mother does not go to work. She stays at home. I have two brothers and one sister. My older brother is working in a factory. My smaller brother and I go to high school. My sister is very young. She goes to kindergarten. Our life is happy in the pretty village.

\section{Lexical Rendering}

1. Five people family I are

8. Old brother I work factory

2. Father I teacher

9. Small brother 1 go-to high school

3. Father I teach English

10. I go-to-high school

4. Mother I go to work

11. Sister I very young

5. Mother I stay at home

6.I two brother have

12. Sister I go-to-kindergarten

7. I one sister have

II. Similarity and Identity chain

13. Family life happy pretty village

a ) five , two, one b ) family (2), father(2), mother(2), brother (3), sister(3)

c ) go - to - work, , stay - at - home, go - to - high school (2) d )l (12) e ) have (2)

Number of Total tokens : 49 Number of Relevant tokens : 34 Number of Central tokens : 28

\section{A sample text from Group B}

There are four adult people in the family. We live in a small city. Father goes to work. I play football in the street . Mother stays at home we have a garden. A good tree is in our yard. We live in Mashad some times. Azad university is near my school . Many study in university . I like university .

\section{Lexical Rendering}

1. Four people adult are family

7. Good tree family garden

2. Family live small city

3. Father go - to - work

4. I play football street

5. Mother - stay - at home

8. Family live Mashad

9. Azad university hear school I

10. Many study university

6. Family have garden

11. I like university

\section{Similarity and Identity chains}

a . family (5), father, mother b. live (2) c . city, Mashad d. 1 (3) e. go - to - work, stay - at - home f. university (3), school

Number of Total tokens : 38 Number of Relevant tokens : 20 Number of Central tokens : 12

\section{Results And Discussion}

A chi-square was applied to see whether there is a significant difference between the frequency of relevant tokens versus peripheral ones in the low-rated group (Group B) in comparison to the high-rated group (Group A). The results indicated that the proportion of relevant tokens to the peripheral ones is higher in group $A$.

The chi-square in relation to $\mathrm{HIl}$ showed the higher proportion of central tokens to non-central ones in group $\mathrm{A}$ in comparison to group $B$, which means the texts which were perceived as more coherent by experienced raters also showed a significantly higher proportion of relevant tokens to peripheral ones and central tokens to non-central ones. 
As stated earlier, an attempt was made to find out the possible relation between the coherence score of texts with the cohesive chains and chain interaction realized in the texts. To do this, two main research questions were asked. In this chapter, the data are analyzed to see whether the null hypotheses are rejected or accepted.

\section{Data Analysis for Hypothesis I}

As it was mentioned, there were two groups of texts used in this study, the high-rated group and the low-rated group. According to the first null hypothesis, it was assumed that the proportion of relevant tokens to the peripheral ones has no relationship with the coherence score of the text. That is, it is expected to see no significant difference

in the frequency of relevant and peripheral tokens between group A and group B. Chi-square is suitable to show whether the frequency of each of these tokens used in group $A$ texts is significantly different from the number of tokens used in group $B$ texts. Table $(I)$ and (2) show the coherence scores and the frequency of tokens in group $A$ and $B$.

\section{Table(1):The Coherence Scores and the Frequency of Tokens in Group A}

\begin{tabular}{|c|c|c|c|c|c|c|}
\hline $\mathrm{N}$ & $\begin{array}{c}\text { Coherence } \\
\text { score }\end{array}$ & $\begin{array}{c}\text { Number of Total } \\
\text { Tokens }\end{array}$ & $\begin{array}{l}\text { Number Of } \\
\text { Peripheral }\end{array}$ & $\begin{array}{l}\text { Number Of } \\
\text { Relevant }\end{array}$ & $\begin{array}{c}\text { Number Of } \\
\text { central }\end{array}$ & $\begin{array}{c}\text { Number Of Non- } \\
\text { central }\end{array}$ \\
\hline 1 & 4.5 & 85 & 23 & 62 & 40 & 22 \\
\hline 2 & 4.5 & 83 & 33 & 50 & 40 & 10 \\
\hline 3 & 4.25 & 80 & 22 & 58 & 43 & 15 \\
\hline 4 & 4.25 & 82 & 19 & 63 & 39 & 24 \\
\hline 5 & 4 & 80 & 26 & 64 & 45 & 19 \\
\hline 6 & 4 & 78 & 20 & 58 & 37 & 21 \\
\hline 7 & 4 & 79 & 26 & 53 & 39 & 14 \\
\hline 8 & 4 & 68 & 9 & 59 & 41 & 18 \\
\hline 9 & 3.75 & 87 & 39 & 48 & 38 & 10 \\
\hline 10 & 3.75 & 69 & 12 & 57 & 36 & 21 \\
\hline 11 & 3.75 & 60 & 10 & 50 & 32 & 18 \\
\hline 12 & 3.5 & 73 & 25 & 48 & 30 & 18 \\
\hline 13 & 3.5 & 49 & 15 & 34 & 28 & 6 \\
\hline 14 & 3.5 & 47 & 15 & 32 & 20 & 12 \\
\hline 15 & 3.5 & 63 & 26 & 37 & 20 & 17 \\
\hline 16 & 3.25 & 50 & 11 & 39 & 22 & 17 \\
\hline 17 & 3.25 & 23 & 5 & 18 & 12 & 6 \\
\hline 18 & 3.25 & 54 & 21 & 33 & 20 & 13 \\
\hline 19 & 3.25 & 73 & 25 & 48 & 28 & 20 \\
\hline 20 & 3 & 69 & 20 & 49 & 32 & 17 \\
\hline 21 & 3 & 58 & 20 & 38 & 26 & 12 \\
\hline 22 & 3 & 75 & 31 & 44 & 30 & 14 \\
\hline 23 & 3 & 67 & 17 & 50 & 39 & 11 \\
\hline 24 & 3 & 53 & 15 & 38 & 25 & 13 \\
\hline 25 & 3 & 48 & 16 & 32 & 22 & 10 \\
\hline
\end{tabular}


Table(2):The Coherence Scores and the Frequency of Tokens in Group B

\begin{tabular}{|c|c|c|c|c|c|c|}
\hline $\mathrm{N}$ & $\begin{array}{c}\text { Coherence } \\
\text { Score }\end{array}$ & $\begin{array}{c}\text { Number of Total } \\
\text { Tokens }\end{array}$ & $\begin{array}{l}\text { Number Of } \\
\text { Peripheral }\end{array}$ & $\begin{array}{l}\text { Number Of } \\
\text { Relevant }\end{array}$ & $\begin{array}{l}\text { Number Of } \\
\text { central }\end{array}$ & $\begin{array}{c}\text { Number Of Non- } \\
\text { central }\end{array}$ \\
\hline 1 & 2.5 & 69 & 31 & 38 & 20 & 18 \\
\hline 2 & 2.5 & 72 & 32 & 40 & 20 & 20 \\
\hline 3 & 2.5 & 78 & 35 & 43 & 25 & 18 \\
\hline 4 & 2.5 & 79 & 35 & 44 & 23 & 21 \\
\hline 5 & 2.5 & 68 & 16 & 52 & 29 & 23 \\
\hline 6 & 2.5 & 59 & 20 & 39 & 28 & 11 \\
\hline 7 & 2.25 & 60 & 21 & 39 & 20 & 19 \\
\hline 8 & 2.25 & 63 & 15 & 48 & 25 & 23 \\
\hline 9 & 2.25 & 54 & 8 & 46 & 25 & 21 \\
\hline 10 & 2 & 44 & 7 & 37 & 24 & 13 \\
\hline 11 & 2 & 48 & 28 & 20 & 11 & 9 \\
\hline 12 & 2 & 50 & 12 & 38 & 18 & 20 \\
\hline 13 & 2 & 50 & 20 & 30 & 20 & 19 \\
\hline 14 & 2 & 59 & 20 & 39 & 15 & 24 \\
\hline 15 & 2 & 48 & 24 & 24 & 12 & 12 \\
\hline 16 & 1.75 & 62 & 33 & 29 & 17 & 12 \\
\hline 17 & 1.75 & 58 & 38 & 30 & 15 & 15 \\
\hline 18 & 1.75 & 53 & 26 & 27 & 14 & 13 \\
\hline 19 & 1.5 & 50 & 19 & 31 & 19 & 12 \\
\hline 20 & 1.5 & 47 & 17 & 30 & 18 & 12 \\
\hline 21 & 1.5 & 32 & 5 & 27 & 12 & 15 \\
\hline 22 & 1.25 & 47 & 22 & 25 & 15 & 10 \\
\hline 23 & 1.25 & 38 & 18 & 20 & 12 & 8 \\
\hline 24 & 1 & 37 & 19 & 18 & 10 & 8 \\
\hline 25 & 1 & 40 & 20 & 20 & 9 & 11 \\
\hline
\end{tabular}

The following table shows the results of the chi-square used for $\mathrm{H} 1$.

Table(3) : The Frequency and the Percentage of Peripheral and relevant Tokens in Group A and Group B

\begin{tabular}{cc|c|c|c} 
& $\begin{array}{c}\text { Count Row pct } \\
\text { Col pct }\end{array}$ & P & R & Row Total \\
\hline A & 501 & 1162 & 1663 \\
Label(A,B0 & 30.1 & 69.9 & 54.7 \\
\cline { 2 - 4 } & & 48.1 & 58.2 & 1375 \\
& B & 541 & 834 & 45.3 \\
& 39.3 & 60.7 & 3038
\end{tabular}




\begin{tabular}{lccc} 
Chi-square & value & df & Significance \\
\hdashline Pearson & 28.38825 & 1 & $0.00066^{--}$ \\
continuity & 27.98062 & 1 & 0.00065
\end{tabular}

As it can be seen in the above table, from 1663 tokens in group A, 1162 were relevant and 501 were peripheral. But in group B, the number of total tokens was 1375. Among these 834 were relevant and 541 were peripheral. As can be seen, the proportion of peripheral to relevant tokens is higher in group $B$ in comparison to group $A$.

The table also shows the percentage of each of these tokens in group A and group B. As it is clear, a higher percentage of relevant tokens were of group $\mathrm{A}$, while the percentage of peripheral tokens was higher in group $\mathrm{B}$. According to these, one can say that the frequency of relevant and peripheral tokens is related to the coherence scores of the text and the highrated texts have a higher proportion of relevant tokens to the peripheral ones in comparison to the low-rated group. It is also shown that our observed chi-square was significantly higher than the critical chi-square and the $p$-value was 0.0006 which indicates the rejection of the first null hypothesis at $\alpha \leq 0.01$ level of significance.

\section{Data Analysis for Hypothesis II}

As it was mentioned before, our second null hypothesis stated that there is no significant difference between group A texts and group B texts in terms of the number of central vs. non-central tokens used. The relevant tokens of a text are either central or non-central. In the null hypothesis, it is assumed that the coherence score of the text is not affected if its frequency of central or con-central tokens changes. To put this hypothesis under investigation, a chi-square was used. The coherence scores and the frequency of tokens is given in Table (2).

The summary of the results of the chi-square computed in relation to $\mathrm{H} 2$ is presented in the following.

Table (4): The Frequency and the Percentage of central and non-central Tokens in

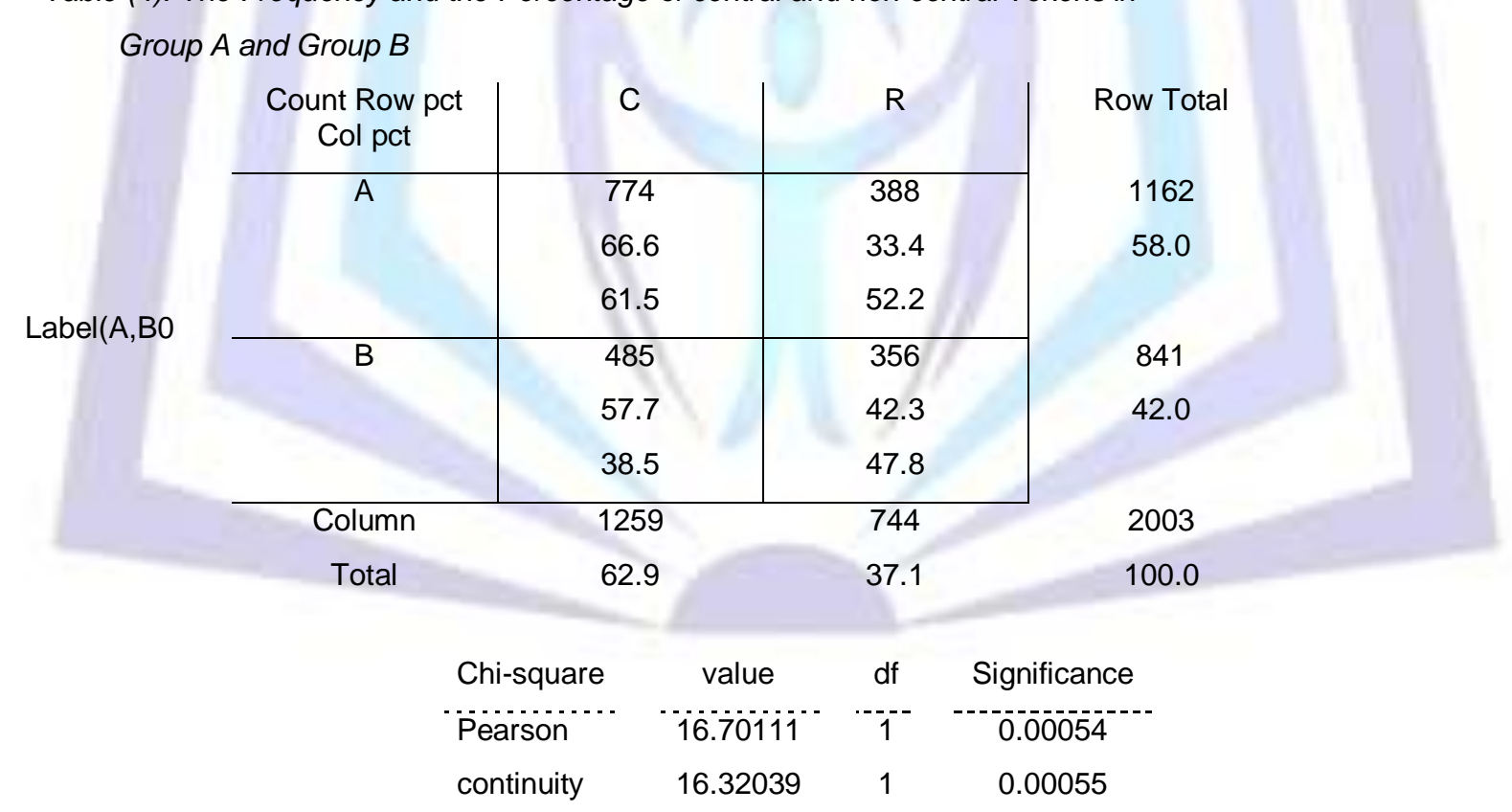

The analysis indicates that the proportion of central tokens to the non-central ones is higher in the high-rated group texts in comparison to the low-rated ones because from 1162 relevant tokens in group A, 774 tokens are central and 388 are non-central, while in group B the total number of relevant tokens is 841 , of which 485 are central and 356 non-central tokens.

Furthermore, as it can be seen in Table 4.2, there is a higher percentage of relevant tokens in group A (66.6\% in group A vs. $57.7 \%$ in group B). In contrast, when we consider the percentage of non-central tokens, it can be observed that the percentage of these tokens is higher in group $B$ in comparison to group $A(42.3 \%$ vs. $33.4 \%$ ).

The chi-square analysis shows that our observed chi-square is significantly higher than the critical chi-square at $\alpha \leq 0.05$ level of significance. Then the second null hypothesis is also rejected at $\alpha \leq 0.01$ level of significance. 


\section{Conclusions, Implications and Suggestions}

Iranian students majoring in English are frequently assigned to writing compositions as a part of their language program. The final purpose of teaching this skill is to help students write texts as close to what an educated native speaker normally writes as possible. That is, we want them to get the ability of writing more united and coherent texts. By assuming that production difficulties arise from not knowing the required vocabulary structures, foreign language teachers may overlook the difficulties students have in making meaning relations within discourse. Though the students may have a good command of language in terms of grammar, vocabulary, etc., the problem in producing unified texts is easily tangible. Unfortunately, there has not been satisfying results available in this area. One possibility is that teachers may not have the needed knowledge about coherence, and the principle on which it is based. The need for more studies is frequently felt in this respect. This study was conducted to shed some lights on the subject.

In this study the researcher tried to find out whether the texts taken as more coherent based on the raters' intuition and perception are more coherent based on the features that Hassan (1989) proposed for such texts. In other words, there were two questions in this study; firstly, whether the texts given a higher coherence scores by the proficient readers of English have higher proportion of relevant tokens to peripheral ones in comparison to the texts with lower coherence scores. Secondly, whether the more coherent texts, based on the raters' perception, have higher proportion of central tokens to non-central ones. The findings of this study show that the tokens of a text and the relations they may have can affect its overall coherence. Then if the writer is aware of this fact, he/she will be more cautious about them. That is, we should pay more attention to this in our teaching pedagogy (particularly writing).

This study showed that there are some relationships between cohesive chain, chain interaction, and coherence of the text. However, the emphasis is on writing rather than speaking. The difference between speech and writing is usually referred to as the difference in the medium of communication in the way that speech is initially handled at the phonetic or phonological levels, whereas writing is handled at the graphic or graphologcial level (Widdowson \& Davies, in Allen \& Corder, 1974). In any speech situation the speaker relies on both verbal and non-verbal elements (Brown \& Yule, 1983). He has access to paralinguistic cues such as voice quality and facial expression; he constantly matches his speech with his intuition and observes his interlocutor's feedback. The writer, however, has no access to immediate feedback and paralinguistic elements. He must rely on language system, that is, words, punctuation, and structure. Therefore, he should use the linguistic elements in such a way as to compensate for the lack of paralinguistic elements available in spoken communication (ibid.).

In order to compensate for such deprivations, the writer must use appropriate syntactic and lexical elements to show semantic and discourse relations between propositions. To Gumpers et al. (in Tannen,1984), cohesive devices are those syntactic forms in written language that to some extent can compensate for those deprivations. The knowledge about the possible interactions that the elements of the text usually have to each other could be of much benefit to the readers and writers.

Most teachers, when evaluating students' writing, have to judge the coherence of the texts. When a teacher tells his students that her writing does not hang together, she should know why it does not hang together and how it should be changed to obtain coherence. Therefore, teachers should possess an understanding of the linguistic resources involved in the coherence of the text. The students' problems also arise when the textbooks they are using do not cohere, or they are not able to find the distance between the two ends of a tie.

The clauses which follow each other provide a context for each other, and this meaningful sequencing of the clauses build up the coherence of the text. An understanding of the linguistic resources about coherence gives teachers and students a notion that they can readily understand the concept of tying things together by means of suitable knots.

If the clauses declared do not have enough connections, the students cannot tolerate the teachers speech and education may not happen skillfully. Students also should be able to talk about the topics and write in the titles. So, the students discourse should be coherent, and the semantic relations should be clear between the concepts they declare or write. Therefore, this study has implications in the area of teaching writing specifically and other skills in general.

In addition to learners and teachers, materials are the other important elements of education. Textbooks as the basic educational materials are very frequently used. Material developers should normally know the texts and the relationships between and within them well in order to select the most suitable ones for different educational purposes. For an elementary level of reading comprehension, for instance, the selected text should have lower complexity and more explicit relations among its elements in comparison to a selected text for intermediate or advanced reading comprehension.

This study had some limitations which should be mentioned. First of all, this study was limited to writing. The problem may have a different realization when the other skills of language are involved. Furthermore, the linguistic features investigated in this study, as the features that affect the coherence of the text, are not the only linguistic features influencing the coherence of the text; for instance-, all instantial lexical cohesion, all organic relations, and all forms of structural cohesion are excluded from the study.

Another problem we had to deal with in this study was the errors committed by the subjects when writing. Most of the errors were interference from the subjects' first language; for example, "I have three brother.", "I have 20 years old.", or "Uncle mine invest our family." Facing this problem, the researcher decided to ignore them if the meaning was clear and, therefore considered these sentences as normal tokens.

\section{REFERENCES}


Appel, R. \& Mysken, P. (1987). Language Contact and Bilingualism. London: Edward:Arnold.

Allen. J.P.B, \& Corder, S.P.(eds.) (1974). The Edinburg Course in Applied inguistics. Vol:3.teaching in Applied Linguistics. London.OUP.

- $\quad$ Biber, D, Johonsson, S., Leech, G., Conard, S., Finnegan, E. (1999). The Longman

1 Grammar of Spoken and Written English. London: Longman.

- $\quad$ Brown. G. . B. Yule. G. ( 1983). Discourse analysis. Bath: Cambridge university Press.

- $\quad$ Butler, C. (2003). Structure and Function: A Guide to Three Major Structural-Functional Theories. Amsterdam: John Benjamin's Publishing Company.

- $\quad$ Chomsky, N. ( I 957). Syntactic Structure. Mouton: The Hague.

- $\quad$ Chomsky, N. (1965. The Theory of Syntax. Cambridge, MA:MT Press

- $\quad$ Cook, V.G. (1 989). Discourse . Oxford: OUP.

- $\quad$ de Beaugrande. R. ( 1980$)$. Text, discourse and process. London: Longman.

- $\quad$ de Beaugrande, R. \& Dressler, W. (1 981). Introduction to Text Linguistics. London and New York: Longman.

- $\quad$ Dong, Y. P. (2005). Psycholinguistics in Foreign Language Teaching. Beijing. Foreign Language Teaching and Research Press.

- $\quad$ Gumpers, J.J., Kaltman, H., \& Catherine, M. (1984). Cohesion in spoken and written discourse. In D. Tannen (Ed.). Ethnic style and the transition to literacy. New Jersey: Ablex Publication Co.

- $\quad$ Halliday, M.A. K. (1 973). Exploration in the Function of language. London: Edward Arnold.

Halliday. M.A.K. (1978). Language us social semiotics: The social interpretation of language and meaning. London: Edward Arnold.

Halliday. M.A. K. ( 1994 ). An Introduction to Functional Grammar (2 ${ }^{\text {nd }}$ edition). London: Edward Arnold.

- $\quad$ Halliday, M.A.K., \& Hassan, R. (1 976). Cohesion in English. English Language Series. London: Longman.

- $\quad$ Halliday, M.A.K., Hassan , R. (1 989). Language, Context and Text: Aspects of Language in Social Semiotic perspective. London: OUP.

- $\quad$ Hassan, R. (1978). On the Notion of Text. Hamburg: H. Buske.

- $\quad$ Hassan, R. (1 989). The texture of a text. In M.A.K. Halliday \& R. Hassan (Eds.). Language Context and Text: Aspect of language in a social-semiotic Perspective

Oxford university press.

Hyland, K. (2005). Teaching and Researching Writing. Foreign Language Teaching and Research Press.

Hymes, D.H. (1967). Models of Interaction of language and Social Setting. Journal of 
Social Issue , 23,

- $\quad$ Labov, W. (1972). Language in the Intensity. Oxford: Blackwell

- $\quad$ LEECH G. N. (1983). Principles of Pragmatics. London: Longman.250pp.

- $\quad$ Liu, C. D. (2003). Text Linguistics for Teachers. Shanghai. Shanghai Foreign Education Language Press.

- $\quad$ McCarthy , M., \& Carter, R.(1994).Language as discourse: Perspective for Language Teaching. London: Longman.

- $\quad$ Rost, M. (2005). Teaching and Researching Listening. Beijing. Foreign Language Teaching and Research Press.

- $\quad$ Sacks, H., Schegloff, E. A., \& Jefferson, G. (1974). "The Simplest System for the Organization of Turn-taking for Conversation." Language, 50, 696-735.

- $\quad$ Schiffrin, D . (1994). Approaches to Discourse .Oxford: Blackwell.

- $\quad$ Tannen, D. (1981), Coherence in Spoken and Written Discourse, Vol.XII. New Jersey: Ablex Publishing Co.

- $\quad$ Thompson, G. ( 1996). An Introduction to Functional Grammar. London: Edward Arnold.

- $\quad$ Thompson, S. (1994). Aspects of cohesion in monologues. Applied Linguistics, 15, 58-75.

- $\quad$ Van Dijk, T.A. (1977). Text and Context: New York. Longman Group LTD.

- $\quad$ Witte, S.P., \& Faigley, L. (1981). Coherence, cohesion and writing quality. College

Composition and Communication. 3 2, 189-204. 